\title{
What are the main symptoms and concerns reported by patients with advanced chronic heart failure? - a secondary analysis of the Palliative care Outcome Scale (POS) and Integrated Palliative care Outcome Scale (IPOS)
}

\author{
Anna Oriani ${ }^{1}$, Ping Guo ${ }^{2}$, Amy Gadoud ${ }^{3}$, Lesley Dunleavy ${ }^{3}$, Pauline Kane ${ }^{2}$, Fliss E. M. Murtagh ${ }^{2,4}$ \\ ${ }^{1}$ Palliative and Supportive Care Clinic, Oncology Institute of Southern Switzerland, Bellinzona, Canton Ticino, Switzerland; ${ }^{2}$ Cicely Saunders \\ Institute of Palliative Care, Policy \& Rehabilitation, Florence Nightingale Faculty of Nursing, Midwifery \& Palliative Care, King's College London, \\ London, UK; ${ }^{3}$ International Observatory on End of Life Care, Lancaster University, Lancaster, UK; ${ }^{4}$ Wolfson Palliative Care Research Centre, Hull \\ York Medical School, University of Hull, York, UK \\ Correspondence to: Anna Oriani, MD, MSc. Palliative and Supportive Care Clinic, Oncology Institute of Southern Switzerland, via Ospedale 1, 6500 \\ Bellinzona, Canton Ticino, Switzerland. Email: anna.oriani.81@gmail.com; anna.oriani@eoc.ch.
}

\begin{abstract}
There is a lack of valid disease-specific patient-reported outcome measures (PROMs) for detecting symptoms and concerns in patients with advanced chronic heart failure (CHF). The Palliative care Outcome Scale (POS) and Integrated Palliative care Outcome Scale (IPOS) are specifically developed to capture the main symptoms and concerns of people severely affected by advanced disease. The aim of this study was to determine whether POS and IPOS captures the main symptoms and concerns selfreported by patients with advanced CHF. A secondary analysis of existing POS/IPOS data collected in three longitudinal studies was conducted. POS and IPOS start with an open-ended question for patients to report their main problems and concerns, followed by subsequent closed questions on a range of symptoms and other concerns. Descriptive statistics were used to report the results. The 102 participants from the three datasets had median age 81 years ( $\mathrm{SD} \pm 9.84$ years); $62 \%$ male; $87 \%$ white. A total of 107 concerns were reported in the first, open POS/IPOS question seeking the patient's main concerns. Of these, $83(77 \%)$ were reflected in the subsequent IPOS/POS closed questions. The high correspondence between the freetext responses and the closed questions indicates that most issues are captured by the POS/IPOS items. In conclusion, the generic versions of POS and IPOS do capture the main problems and concerns of patients with advanced CHF. Minor adaptations and further psychometric validation of POS and IPOS are needed in this population.
\end{abstract}

Keywords: Outcome assessment (Health Care); Patient Health Questionnaire; advanced chronic heart failure (advanced CHF); palliative care; secondary analysis

Submitted May 01, 2019. Accepted for publication Aug 12, 2019.

doi: 10.21037/apm.2019.08.10

View this article at: http://dx.doi.org/10.21037/apm.2019.08.10

\section{Introduction}

Chronic heart failure (CHF) remains one of the major causes of morbidity and mortality globally (1). As advances in treatments have prolonged life, considerably more attention needs to be paid to improving quality of life (2). CHF has a significant impact on physical, psychological and social well-being, and there is substantive literature describing symptom distress and unmet needs among people with CHF, especially towards the end of life (3).

Patients affected by heart failure experience a gradual decline, punctuated by episodes of acute deterioration and eventually sudden death or death owing to progressive heart failure (4). Generally, three phases of disease can 
be described: a relatively stable primary phase; then one or more secondary phases of decline requiring increased utilization of hospital care; and ultimately, a tertiary terminal phase of inexorable deterioration (advanced CHF) (4). However, it may be difficult to know when the third phase is being reached.

The diagnosis of advanced CHF depends on patient's symptoms, prognostic markers, and presence of end-organ damage. Advanced CHF encompasses patients who remain severely symptomatic despite optimal management (5). Patients with advanced CHF frequently experience symptoms of breathlessness (6-8), fluid retention (pulmonary or systemic congestion) (7), pain (9), and fatigue at rest or on minimal exertion $(7,10-12)$, and cardiac cachexia (5). A variety of changes in emotional, social and spiritual wellbeing are described by this group of patients (13). However, these symptoms and other concerns are poorly recognised and addressed (14), both because of the reluctance to face deterioration and the lack of specialist knowledge in this final illness trajectory (15).

The literature identifies a lack of valid disease-specific patient-reported outcome measures (PROMs) for detecting symptoms and concerns in patients with advanced $\mathrm{CHF}$ $(16,17)$. There are different questionnaires for CHF with good evidence of reliability, validity, responsiveness, and feasibility in the CHF population (18). But although the Minnesota Living with Heart Failure Questionnaire and the Kansas City Cardiomyopathy Questionnaire meet these criteria best $(11,19,20)$, no measures have been fully validated for the use in far advanced disease (14).

The Palliative care Outcome Scale (POS) and Integrated Palliative care Outcome Scale (IPOS) are designed to measure those symptoms and concerns most often reported by people with advanced illness; physical and psychological symptoms, social and spiritual aspects, communication, information and practical needs (21). POS and IPOS have been developed from interviews with patients experiencing advanced illness, and start with an open-ended question ('what have been your main problems or concerns over the past week?') for patients to report their main problems and concerns, followed by subsequent closed questions on a range of symptoms and other concerns which are important to patients in advanced illness (21). POS demonstrates good construct validity and test/retest reliability (22). Internal consistency is also good (22). IPOS represents a refinement of POS to capture more details about symptoms and for this reason, it differs from POS in a small number of items (23). IPOS is now available for clinical use, and a refined version is currently undergoing full validation in the United Kingdom (24). Both patient and proxy versions of POS and IPOS are available, making it possible to use even when someone is very unwell (21). Both questionnaires can be used across different settings: home, nursing home, hospital, and hospice (21) and are freely available on a web platform www.pos-pal.org for clinical and research use. POS and IPOS have been used for patients affected by CHF (21), although few studies have been performed to evaluate them in advanced CHF $(14,25)$.

This study therefore aims to determine whether POS and IPOS captures the main symptoms and concerns selfreported by patients with advanced CHF.

\section{Methods}

Secondary analysis was conducted, using existing data collected in three studies in which POS and IPOS were used among patients affected by CHF. Two studies were identified by reviewing the studies included in two recent systematic reviews about the use of POS $(23,26)$. Both reviews aimed to appraise the general use of POS in the context and nature of its use and identify strengths and weaknesses of this patient reported outcome measure $(23,26)$. The third study about the use of IPOS in advanced CHF (14), was identified by consulting the CHF group working at the Cicely Saunders Institute of Palliative Care, Policy and Rehabilitation, King's College London.

The characteristics of the studies are reported in Table 1. All the three studies provided longitudinal data, over varying lengths of time. For this secondary analysis, only the first, baseline questionnaire (POS or IPOS) was used, for consistency across studies.

Both quantitative and qualitative analyses were undertaken. For the analysis of the first open question of the POS and IPOS, thematic analysis was used to search for and identify themes (28). Thematic analysis is an approach to identify themes that emerge through the analysis of the textual data (29). A theme can be defined as a pattern in the information that describes and organizes the possible observations (30). Themes are not preconceived, but emerge from the data (30). The use of this methodology is based on the following steps (29,30): reading and re-reading the qualitative data, coding this data, developing a coding frame, applying the coding frame to all data, re-iterating the coding frame to encompass all themes, and then analyzing and interpreting these themes.

Descriptive statistics are used to report the answers to 
Table 1 Characteristics of the three studies included in the secondary analysis

\begin{tabular}{|c|c|c|c|}
\hline $\begin{array}{l}\text { Study } \\
\text { characteristics }\end{array}$ & Dataset I (25) & Dataset II (14) & Dataset III (27) \\
\hline Setting & Hospice & 2 nurse-led CHF clinics & 3 renal unit \\
\hline Patients & $\begin{array}{l}40 \text { patients with advanced } \\
\text { chronic heart failure with } \\
\text { conserved or reduced ejection } \\
\text { fraction }\end{array}$ & $\begin{array}{l}25 \text { patients affected by CHF, with NYHA } \\
\text { functional class III or IV. Patient inclusion criteria } \\
\text { were developed according to the European } \\
\text { Society of Cardiology's CHF definition }\end{array}$ & $\begin{array}{l}37 \text { patients with CHF out of a total of } 74 \\
\text { patients with end-stage renal disease } \\
\text { and who were being managed without } \\
\text { dialysis }\end{array}$ \\
\hline
\end{tabular}

CHF, chronic heart failure; NYHA, New York Heart Association; IPOS, Integrated Palliative care Outcome Scale.

the IPOS and POS closed questions. Answers to the open question of POS and IPOS ('what have been your main problems or concerns over the past week?') were then compared with the POS/IPOS items. In this way, concerns expressed by the participants, but not included in POS/IPOS closed questions, could be identified.

To assess the rigor of the coding and cross-check the coding and thematic analysis, two researchers (Anna Oriani and Amy Gadoud) analyzed the data independently, and then compared. A third impartial researcher (Lesley Dunleavy) was consulted in the event of disagreement. Missing data was very low (less than $5 \%$ ), assumed to be at random and excluded from the analysis (29).

\section{Ethical concerns}

The Research and Innovation Office of King's College Hospital, London and the UK Health Research Authority confirmed that additional ethical approval was not needed, as this was within the scope of the original ethical approval for all three studies. All the three previous studies have been approved by each local medical ethics committee and all the participants have signed a consent form.

\section{Results}

Data came from 102 participants. Patients' characteristics are reported in Table 2. Mean age was 81 years $(\mathrm{SD} \pm 9.84$ years), $62 \%$ were male and $87 \%$ white. Baseline New York Heart Association (NYHA) score was available for 65 patients: 19 patients were classified NYHA II, 37 patients were classified NYHA III, and 9 patients were classified

\section{NYHA IV.}

In total, 88/102 (86\%) completed the POS or IPOS questionnaire, with 19 patients providing three responses to the first open question, 18 providing two, 26 providing one and 25 patients providing no concerns. A total of 107 concerns were reported in the first open question. Of these concerns, 83 (77\%) were reflected in the subsequent IPOS/ POS closed questions. Most issues raised in the first open question were subsequently also captured in the closed POS/IPOS items (see Table 3).

In the analysis of the first open question, we identified some themes as unique concerns, as for instance concerns caused by other co morbidities expressed as "kidney infection" or "COPD". Unique concerns about the poor quality of life, loneliness and self-esteem were also reported: "I feel very ill"; "Feeling and being sick all the time" or "More frustrated"; "Ever decreasing the quality of life" or "Have tired enough of life"; "Loss of independence" or "Losing touch with people, isolation". Other themes identified as unique concerns included symptoms caused by fluid retention, nocturnal breathlessness, itch and cough.

Breathlessness was reported by 14 (16\%), especially when moving: "Lack of breath when I move"; "Shortness of breath when I walk or exert myself". Seven patients (8\%) reported anxiety, described as "Feeling anxious all the time". Among patients who reported pain ( $\mathrm{n}=9 ; 10 \%)$, only one reported angina as a major concern, writing as having been "Frightened when I had angina, and I was on my own". Mobility problems have been described differently by patients, such as: "Loss of balance", "Disappointed by travelling limitations" or "Difficulty in walking more than 50 yards." 
Table 2 Participants' characteristics $(\mathrm{N}=102)$

\begin{tabular}{|c|c|}
\hline Variables & $\begin{array}{l}\text { Numbers and } \\
\text { percentages }\end{array}$ \\
\hline \multicolumn{2}{|l|}{ Demographic characteristics } \\
\hline Age & $\begin{array}{l}\text { Mean: } 81 \text { years; } \\
\text { SD: } \pm 9.84 \text { years }\end{array}$ \\
\hline \multicolumn{2}{|l|}{ Gender } \\
\hline Male & $63(62 \%)$ \\
\hline Female & $39(38 \%)$ \\
\hline \multicolumn{2}{|l|}{ Ethnicity } \\
\hline White & $89(87 \%)$ \\
\hline Black & $6(6 \%)$ \\
\hline South Asia & $3(3 \%)$ \\
\hline Chinese & $1(1 \%)$ \\
\hline Other & $3(3 \%)$ \\
\hline \multicolumn{2}{|l|}{ Co-morbidities } \\
\hline Renal disease & $88(86 \%)$ \\
\hline $\begin{array}{l}\text { Ischemic heart disease (including myocardial } \\
\text { infarction) }\end{array}$ & $61(60 \%)$ \\
\hline Diabetes mellitus & $37(36 \%)$ \\
\hline Hypertension & $14(14 \%)$ \\
\hline Other (peripheral or central) vascular diseases & $25(25 \%)$ \\
\hline Atrial fibrillation & $17(17 \%)$ \\
\hline Thromboembolism & $1(1 \%)$ \\
\hline Valve defects & $7(7 \%)$ \\
\hline Malignancies & $19(19 \%)$ \\
\hline COPD & $15(15 \%)$ \\
\hline Depression & $5(5 \%)$ \\
\hline Liver disease & $1(1 \%)$ \\
\hline
\end{tabular}

COPD, chronic obstructive pulmonary disease.

\section{Discussion}

This secondary analysis found that the generic versions of POS and IPOS capture a high proportion of the symptoms and concerns of patients affected by advanced CHF. There is a high correspondence between the free-text responses to the first open question and the subsequent closed questions in POS/IPOS. Only a limited number of additional concerns were gathered from the first open question of POS/IPOS. Among these unique concerns, patients
Table 3 Symptoms and concerns reported by patients in the first open question of POS/IPOS

\begin{tabular}{lc}
\hline $\begin{array}{l}\text { Symptoms and concerns } \\
\text { (categorized into themes) }\end{array}$ & $\begin{array}{c}\text { Number of } \\
\text { patients, N (\%) }\end{array}$ \\
\hline Poor mobility & $21(24 \%)$ \\
Shortness of breath & $14(16 \%)$ \\
Fatigue & $12(14 \%)$ \\
Pain & $9(10 \%)$ \\
Problems with other medical conditions & $9(10 \%)$ \\
Practical matters related to illness & $8(9 \%)$ \\
Feeling anxious & $7(8 \%)$ \\
Low quality of life & $4(5 \%)$ \\
Fluid retention or edema & $4(5 \%)$ \\
Other symptoms & $3(3 \%)$ \\
Poor appetite & $3(3 \%)$ \\
Loneliness & $2(2 \%)$ \\
Lack of concentration/poor memory & $2(2 \%)$ \\
Concerns about self-esteem & $2(2 \%)$ \\
Bowel-related concerns & $1(1 \%)$ \\
Drowsiness & $1(1 \%)$ \\
Itch & $1(1 \%)$ \\
Nough & $1(1 \%)$ \\
\hline Patients sleeping well & $1(1 \%)$ \\
Depression & $1(1 \%)$ \\
\hline
\end{tabular}

Patients had the chance to provide 3 answers to the first open IPOS/POS question. Some patients provided 3 answers, some 2 or 1 and some.

were mostly distressed by co-morbidities, fluid retention, nocturnal breathlessness, loneliness, itch, cough, and sleep disturbance.

In reference to the POS and IPOS closed questions, patients reported breathlessness, fatigue and drowsiness as most prevalent. Pain, sore and dry mouth and gastrointestinal symptoms (nausea, constipation, and poor appetite) were also common.

This secondary analysis found that some participants reported the same symptom or concern both in the free-text answers and in the closed questions. This may be due to different reasons, including the desire to emphasize a highly burdensome symptom, or to report it as a high priority. The 
responses to the open-ended question provide reassurance that many of the relevant issues are captured by the POS/ IPOS items, highlighting relatively few problems or concerns not covered by the closed questions. However, the first open question remains important to uncover the main concerns which the patient prioritizes, and report these in their own words.

We tried to identify all existing POS/IPOS datasets which included over $30 \%$ of participants with advanced CHF. The use of three datasets together is useful; it increases the size of the analyzed dataset, and thus the strength of our findings. However, this was a secondary analysis of data collected to address primary hypotheses that were different from our study. The studies were conducted for diverse primary aims and some important data were therefore missing. For instance, it was not possible to know the NHYA stage for all the patients. Moreover, dataset III was collected specifically to study the trajectory of symptoms in patients affected by end-stage renal failure; a potentially different population who may have a higher proportion of co-morbidities. However, from this dataset we selected only the patients with $\mathrm{CHF}$ as a specific co-morbidity. Given that the prevalence of the symptoms reported by this patient cohort is similar to the ones described in literature $(11,31)$, however, inclusion of this dataset was justified.

In conclusion, POS and IPOS assess palliative care symptoms and concerns, and are specifically designed as an outcome measure for use among people severely affected by any chronic disease (32). This analysis of the generic version of POS and IPOS in patients affected by advanced CHF, showed that these two PROMs comprehensively reflect the main problems and concerns of these patients, and the open question can capture any remaining unique concerns. These findings are consistent with the literature on the most prevalent concerns of this secondary analysis cohort of patients. Minor adaptations and further psychometric validation of POS and IPOS are needed in patients with advanced $\mathrm{CHF}$ to further determine the value of these measures in this population.

\section{Acknowledgments}

Mary Brice: RN, MSc Cardiology, St Christopher's Hospice, UK.

\section{Footnote}

Conflicts of Interest: The authors have no conflicts of interest to declare.

Ethical Statement: The authors are accountable for all aspects of the work in ensuring that questions related to the accuracy or integrity of any part of the work are appropriately investigated and resolved.

\section{References}

1. Ponikowski P, Voors AA, Anker SD, et al. 2016 ESC Guidelines for the diagnosis and treatment of acute and chronic heart failure: The Task Force for the diagnosis and treatment of acute and chronic heart failure of the European Society of Cardiology (ESC). Developed with the special contribution of the Heart Failure Association (HFA) of the ESC. Eur J Heart Fail 2016;18:891-975.

2. Bekelman DB, Havranek EP, Becker DM, et al. Symptoms, depression, and quality of life in patients with heart failure. J Card Fail 2007;13:643-8.

3. Abshire M, Xu JY, Himmelfarb CD, et al. Symptoms and fear in heart failure patients approaching end of life: a mixed methods study. J Clin Nurs 2015;24:3215-23.

4. Jaarsma T, Beattie JM, Ryder M, et al. Palliative care in heart failure: A position statement from the palliative care workshop of the Heart Failure Association of the European Society of Cardiology. Eur J Heart Fail 2009;11:433-43.

5. Crespo-Leiro MG, Metra M, Lund LH, et al. Advanced heart failure: a position statement of the Heart Failure Association of the European Society of Cardiology. Eur J Heart Fail 2018;20:1505-35.

6. Albert N, Trochelman K, Li J, et al. Signs and symptoms of heart failure: Are you asking the right questions? Am J Crit Care 2010;19:443-52.

7. Barnes S, Gott M, Payne S, et al. Prevalence of symptoms in a community-based sample of heart failure patients. J Pain Symptom Manage2006;32:208-16.

8. Herr JK, Salyer J, Flattery M, et al. Heart failure symptom clusters and functional status - a cross-sectional study. J Adv Nurs 2015;71:1274-87.

9. Nordgren L, Sörensen S. Symptoms experienced in the last six months of life in patients with end-stage heart failure. Eur J Cardiovasc Nurs 2003;2:213-7.

10. Gwaltney CJ, Slagle AF, Martin M, et al. Hearing the voice of the heart failure patient: key experiences identified in qualitative interviews. Br J Cardiol 2012;19:25.

11. Zambroski CH, Moser DK, Bhat G, et al. Impact of symptom prevalence and symptom burden on quality of life in patients with heart failure. Eur J Cardiovasc Nurs 
2005;4:198-206.

12. Song EK, Moser DK, Rayens MK, et al. Symptom clusters predict event-free survival in patients with heart failure. J Cardiovasc Nurs 2010;25:284-91.

13. Leeming A, Murray SA, Kendall M. The impact of advanced heart failure on social, psychological and existential aspects and personhood. Eur J Cardiovasc Nurs 2014;13:162-7.

14. Kane PM, Daveson BA, Ryan K, et al. Feasibility and acceptability of a patient-reported outcome intervention in chronic heart failure. BMJ Support Palliat Care 2017;7:470-9.

15. Fitzsimons D, Mullan D, Wilson JS, et al. The challenge of patients' unmet palliative care needs in the final stages of chronic illness. Palliat Med 2007;21:313-22.

16. Opasich C, Gualco A, De Feo S, et al. Physical and emotional symptom burden of patients with end-stage heart failure: what to measure, how and why. J Cardiovasc Med (Hagerstown) 2008;9:1104-8.

17. Waller A, Girgis A, Davidson PM, et al. Facilitating needsbased support and palliative care for people with chronic heart failure: preliminary evidence for the acceptability, inter-rater reliability, and validity of a needs assessment tool. J Pain Symptom Manage 2013;45:912-25.

18. Kelkar AA, Spertus J, Pang P, et al. Utility of PatientReported Outcome Instruments in Heart Failure. JACC Heart Fail 2016;4:165-75.

19. Green CP, Porter CB, Bresnahan DR, et al. Development and evaluation of the Kansas City Cardiomyopathy Questionnaire: a new health status measure for heart failure. J Am Coll Cardiol 2000;35:1245-55.

20. Riegel B, Moser DK, Glaser D, et al. The Minnesota Living With Heart Failure Questionnaire: sensitivity to differences and responsiveness to intervention intensity in a clinical population. Nurs Res 2002;51:209-18.

21. Higghinson I. Palliative Care Outcome Scale. 2012. Available online: http://pos-pal.org/maix/. Accessed 27 December 2017.

22. Hearn J, Higginson IJ. Development and validation of a core outcome measure for palliative care: the palliative care outcome scale. Palliative Care Core Audit Project Advisory Group. Qual Health Care 1999;8:219-27.

23. Bausewein C, Le Grice C, Simon S, et al. The use of two common palliative outcome measures in clinical care and research: a systematic review of POS and STAS. Palliat
Med 2011;25:304-13.

24. Schildmann EK, Groeneveld EI, Denzel J, et al. Discovering the hidden benefits of cognitive interviewing in two languages: The first phase of a validation study of the Integrated Palliative care Outcome Scale. Palliat Med 2016;30:599-610.

25. Brice M, Martin A, Hansford P, et al. Heart failure care or palliative care? Patients want and need both. BMJ Support Palliat Care 2016;6:387.

26. Collins ES, Witt J, Bausewein C, et al. A Systematic Review of the Use of the Palliative Care Outcome Scale and the Support Team Assessment Schedule in Palliative Care. J Pain Symptom Manage 2015;50:842-53.e19.

27. Murtagh FE, Addington-Hall JM, Edmonds PM, et al. Symptoms in advanced renal disease: a cross-sectional survey of symptom prevalence in stage 5 chronic kidney disease managed without dialysis. J Palliat Med 2007;10:1266-76.

28. Bryman A. Social research methods. Oxford University Press, 2015.

29. Bowling A, Ebrahim S. Handbook of health research methods. Investigation, measurement and analysis. McGraw-Hill Education, 2005.

30. Fereday J, Muir-Cochrane E. Demonstrating Rigor Using Thematic Analysis: A Hybrid Approach of Inductive and Deductive Coding and Theme Development. Int J Qual Methods 2006;5:80-92.

31. Olano-Lizarraga M, Oroviogoicoechea C, ErrastiIbarrondo B, et al. The personal experience of living with chronic heart failure: a qualitative meta-synthesis of the literature. J Clin Nurs 2016;25:2413-29.

32. Higginson I. The development, validity, reliability and practicality of a new measure of palliative care: the Support Team Assessment Schedule. PhD thesis, University College London, London, 1992. Available online: http:// discovery.ucl.ac.uk/1317889/1/296225.pdf

Cite this article as: Oriani A, Guo P, Gadoud A, Dunleavy L, Kane P, Murtagh FE. What are the main symptoms and concerns reported by patients with advanced chronic heart failure?-a secondary analysis of the Palliative care Outcome Scale (POS) and Integrated Palliative care Outcome Scale (IPOS). Ann Palliat Med 2019;8(5):775-780. doi: 10.21037/ apm.2019.08.10 